\title{
Dithiadiazolyl radicals as building blocks for molecular materials
}

\author{
D. A. Haynes \\ Department of Chemistry \& Polymer Science, Stellenbosch University, P. Bag X01, Matieland, Stellenbosch, South Africa. \\ dhaynes@sun.ac.za
}

A particular family of stable organic radicals, the 1,2,3,5-dithiadiazolyls (DTDAs), has been the focus of much research due to their potential as building blocks for molecular materials, in particular materials with interesting magnetic or conducting properties [1]. However, DTDAs frequently dimerise in the solid state via an interaction known as pancake bonding (Fig. 1 left) [2], rendering them diamagnetic. Our various efforts to understand and overcome this pancake bonding interaction will be presented.

The potential of co-crystallisation as a means to overcome dimerisation in DTDAs has been investigated [3]. Thus far, all DTDADTDA co-crystals characterised crystallise as pancake-bonded dimers. This has been probed computationally. In related studies, control of polymorph and crystal morphology of a monomeric DTDA by co-sublimation has been demonstrated.

A DTDA has been included in a porous metallocyclic host in an effort to produce materials with interesting magnetic behaviour through interaction between the radical and the host (Fig. 1 right) [4]. The coordination of DTDAs to metalloporphyrins has also been extensively investigated. One particularly interesting DTDA-porphyrin polymer will be discussed [5]. In these systems, dimerisation has been overcome either by restriction of space available for the radical, or by formation of a DTDA-metal bond.

In order to gain a deeper understanding of pancake bonding, experimental charge density analysis has been carried out on a number of DTDA homodimers, heterodimers and monomers [6]. These data, as well as various computational results, have been assessed to probe the nature of the pancake bonds in DTDAs, and reveal how pancake bonds differ from both covalent bonds and conventional intermolecular interactions.

It is clear that DTDAs show great potential as building blocks in the construction of molecular materials.
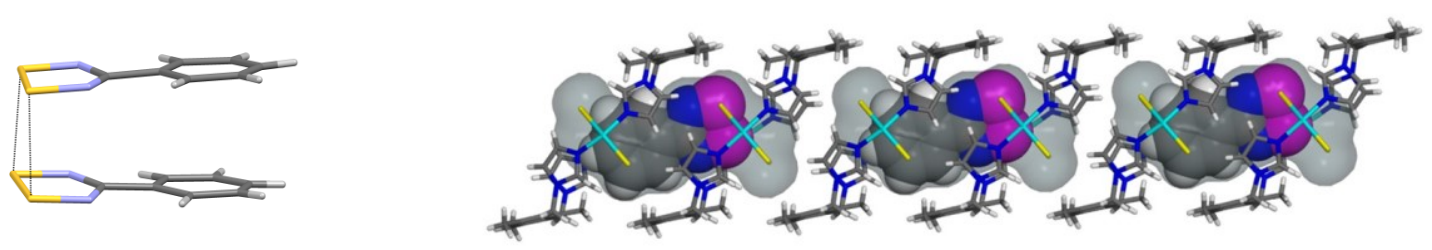

Figure 1. (left) A DTDA pancake-bonded dimer. (right) DTDA included in a porous metallocycle.

[1] Haynes, D. A. (2011). CrystEngComm 13, 4793.

[2] (a) Beneberu, H. Z., Tian, Y.-H. \& Kertesz, M. (2012). Phys. Chem. Chem. Phys. 14, 10713. (b) Cui, H., Lischka, H., Beneberu, H. Z. \& Kertesz, M. (2014). J. Am. Chem. Soc. 136, 12958. (c) Preuss, K. (2014). Polyhedron 79, 1-15.

[3] (a) Alan,C., Haynes, D. A., Pask, C. M. \& Rawson, J. M. (2009). CrystEngComm, 11, 2048. (b) Robinson, S. W., Haynes, D. A. \& Rawson, J. M. (2013). CrystEngComm, 15, 10205.

[4] Nikolayenko, V. I., Barbour, L. J., Arauzo, A., Campo, J., Rawson, J. M. \& Haynes, D. A. (2017) Chem. Commun., 53, 11310.

[5] Haynes, D. A., van Laeren, L. J. \& Munro, O. Q. (2017). J. Am. Chem. Soc., 139, 14620.

[6] (a) Domagała, S., Kość, K., Robinson, S. W., Haynes, D. A. \& Wozniak, K. (2014). Cryst. Growth Des. 14, 4834. (b) Domagała, S. \& Haynes, D.A. (2016). CrystEngComm, 18, 7116. (c) Voufack, A. B., Claiser, N., Dippenaar, A. B., Esterhuysen, C., Haynes, D. A, Lecomte, C. \& Souhassou, M. Manuscript in preparation.

Keywords: molecular materials; thiazyl radicals; magnetism; charge density; co-crystals

The National Research Foundation (South Africa), Sasol and Stellenbosch University are thanked for funding. 